\title{
Clear cell adenocarcinoma of the male urethra: clinical case report
}

\author{
Adenocarcinoma de células claras da uretra masculina: relato de caso clínico \\ Juliana Sinezio Santos ${ }^{1} \odot$, Gabriella Oliveira Mendes' ${ }^{1}$, Fernando Sabino Marques Monteiro 1,2,3.
}

\begin{abstract}
Primary clear cell adenocarcinoma of the urethra is a rare malignancy and most of the cases described are in women. The symptomatology is similar to other tumors of the urethra. Because it is a rare malignancy and the consequent lack of trials in the medical literature, there is no data about the most appropriate treatment for this disease. We aim to describe a clinical case of primary clear cell adenocarcinoma of the urethra in a young male patient. This is a 36-year-old male diagnosed with primary clear cell adenocarcinoma of the urethra whom underwent a surgery for localized disease and about 30 months later he had a local and systemic recurrence. He was treated with platinum-based chemotherapy and presented an excellent clinical and radiological response. Although there is no optimal treatment for this malignancy, in the case of metastatic disease, systemic platinum-based chemotherapy should be considered an appropriate option.
\end{abstract}

Keywords: Adenocarcinoma, Clear Cell; Urethral Neoplasms; Male Urogenital Diseases; Systemic Management.

\section{RESUMO}

O adenocarcinoma de células claras primário da uretra é uma doença maligna rara e a maioria dos casos descritos são em mulheres. A sintomatologia é semelhante a outros tumores da uretra. Por se tratar de uma neoplasia rara e a consequente falta de ensaios na literatura médica, não existem dados sobre o tratamento mais adequado para esta doença. Nosso objetivo é descrever um caso clínico de adenocarcinoma de células claras primário da uretra em um paciente jovem do sexo masculino. Trata-se de um homem de 36 anos com diagnóstico de adenocarcinoma de células claras primário da uretra que foi submetido a uma cirurgia para doença localizada e cerca de 30 meses depois apresentou recorrência local e sistêmica. Foi tratado com quimioterapia à base de platina e apresentou excelente resposta clínica e radiológica. Embora não haja um tratamento ideal para essa malignidade, no caso de doença metastática, a quimioterapia sistêmica à base de platina deve ser considerada uma opção apropriada.

Descritores: Adenocarcinoma de células claras; Neoplasias uretrais; Doenças urogenitais masculinas; Manejo sistêmico.

1. Hospital Santa Lucia, Oncology Department - Brasília - Distrito Federal - Brazil.

2. Latin American Cooperative Oncology Group - LACOG, Oncology - Porto Alegre - Rio Grande do Sul - Brazil.

3. Hospital Universitário de Brasília - HUB, Oncology - Brasília - Distrito Federal - Brazil.

Financial support: none to declare.

Conflicts of interest: The authors declare no conflict of interest relevant to this manuscript

Correspondence author: Juliana Sinezio Santos, Hospital Santa Lucia, Oncology Department - Brasília - Distrito Federal - Brazil.

E-mail: julianasnz@gmail.com 


\section{INTRODUCTION}

Primary urethral tumors are uncommon, especially clear cell adenocarcinoma (CCA), which is most commonly described in females, ${ }^{1,2}$ with only nine cases reported in men since 1981 (Table 1). CCA presents clinically as other urethral carcinomas, with obstructive symptoms, hematuria, and urinary tract infections. ${ }^{3}$ The origin and risk factors for this malignancy are unknown. So far, it is known that is an aggressive disease, that in most cases the diagnosis is with the localized disease and, in this condition, local surgical treatment would be the most appropriate approach. ${ }^{1}$

We report a clinical case of primary clear cell adenocarcinoma of the urethra (CCAU) in male. This is the tenth patient with this malignancy found in the literature and the one with the longest disease-free survival after local primary tumor surgery. This is also the first case with complete radiological response after platinum-based systemic chemotherapy.

\section{CASE REPORT}

This is a 36-year-old white man previously healthy, social drinker, non-smoker, with no comorbidities or previous surgery, and also no family history of cancer. He presented an amorphous material during urination and the urine analysis ruled out malignancy. An urethrocystoscopy was performed showing that the urethral segment had nodular lesions protruding into the urethral lumen, hindering the progression of the device during the exam. These lesions were partially resected and the analysis showed epithelial proliferation with cellular atypia, areas of necrosis and $\mathrm{Ki}-67$ 30\%. A ${ }^{18} \mathrm{~F}$ - fluorodeoxyglucose positron emission tomography ( $\left.{ }^{18} \mathrm{~F}-\mathrm{FDG} \mathrm{PET} / \mathrm{CT}\right)$ showed narrowing area with hypermetabolism and enhancement in the membranous urethra of about 10.0mm (SUV: 9.7). No other loco-regional or distant lesions were demonstrated on ${ }^{18}$ F-FDG PET/CT.

The patient underwent transurethral resection (TUR) and the lesion was totally resected. The pathological analysis of the lesion was compatible with primary clear cell adenocarcinoma of the urethra without invasion of the muscle layer (Figures 1A, 1B and 1C). The immunohistochemistry (IHC) demonstrated a Ki$6760 \%$ and positivity for cytokeratin, PAX-8, HNF1B, and focal GATA-3 (Figure 1D).

A partial urethrectomy was performed with proximal segment ureterostomy due to the difficulty of performing end-to-end anastomosis. After the surgery, the patient presented with weak urinary stream and serial urethra dilations were needed. Despite this, he maintained renal function preserved with serum creatinine values ranging from $0,76 \mathrm{mg} / \mathrm{dl}$ to $0,91 \mathrm{mg} / \mathrm{dl}$. The patient also maintained a good urinary continence and sexual activity. He was followed every three months with computed tomography (CT) of the chest, magnetic resonance imaging (MRI) of abdomen and pelvis, and cytopathological analysis of urine.

After 2.5 years of follow-up, the patient presented with severe right pelvic pain. A pelvis CT showed an irregular lytic bone lesion in right ischium. $A^{18}$ F-FDG PET/CT was performed in 03/15/2019 and showed a hypermetabolic lesion (SUV: 11.1) on the surgical bed of the urethra and another hypermetabolic lytic lesion (SUV: 15.5) with soft tissue component measuring $31 \mathrm{~mm}$ between the pubis and right ischium compatible with neoplastic involvement (Figures $2 \mathrm{~A}$ and $3 \mathrm{~A}$ ). A bone lesion biopsy was performed, and the pathological analysis demonstrated poorly differentiated metastatic carcinoma and IHC showed PAX-8, napsin A and CA-125 coexpression suggesting metastatic CCA of urogenital tract origin.

Considering the clinical condition of the patient as well as the results of the exams, he underwent systemic chemotherapy with cisplatin $35 \mathrm{mg} / \mathrm{m}^{2}$ plus gemcitabine $1000 \mathrm{mg} / \mathrm{m}^{2}$ both in day 1 and 8 every 3 weeks for a total of 6 cycles. After the first cycle, he evolved with complete bone pain improvement. The patient had an excellent tolerance of entire treatment and had no other complications. After

Table 1. Summary of Cases of Clear Cell Adenocarcinoma of the Male Urethra

\begin{tabular}{lcccccc}
\hline Reference & Year & Age & Stage & Inicial therapy & Recurrence & Survival \\
\hline Cantrell et al $^{2}$ & 1981 & 68 & Locally advanced & Radiotherapy & 20 months & 29 months \\
Oliva et $\mathrm{al}^{7}$ & 1996 & 46 & Unknown & Unknown & Unknown & Unknown \\
Seseke et $\mathrm{al}^{14}$ & 2001 & 57 & Localized & Surgery & 10 months & 30 months \\
Gogus et $\mathrm{al}^{13}$ & 2003 & 44 & Locally advanced & Surgery & 5 months & 10 months \\
Varachhia et al $^{11}$ & 2009 & 68 & Unknown & No treatment & - & 2 months \\
Liu et al $^{6}$ & 2012 & 37 & Metastatic & Chemotherapy & - & 29 months \\
Gandhi et al $\left.\right|^{9}$ & 2012 & 55 & Localized & Surgery & Unknown & Unknown \\
Lewis et al $^{12}$ & 2015 & 36 & Localized & Brachytherapy & Unknown & Unknown \\
Sugimura et al & 2018 & 56 & Localized & Surgery & Unknown & Unknown \\
Santos et al & 2020 & 36 & Localized & Surgery & 30 months & NR \\
\hline
\end{tabular}

NR: Not reached; a: Present report 


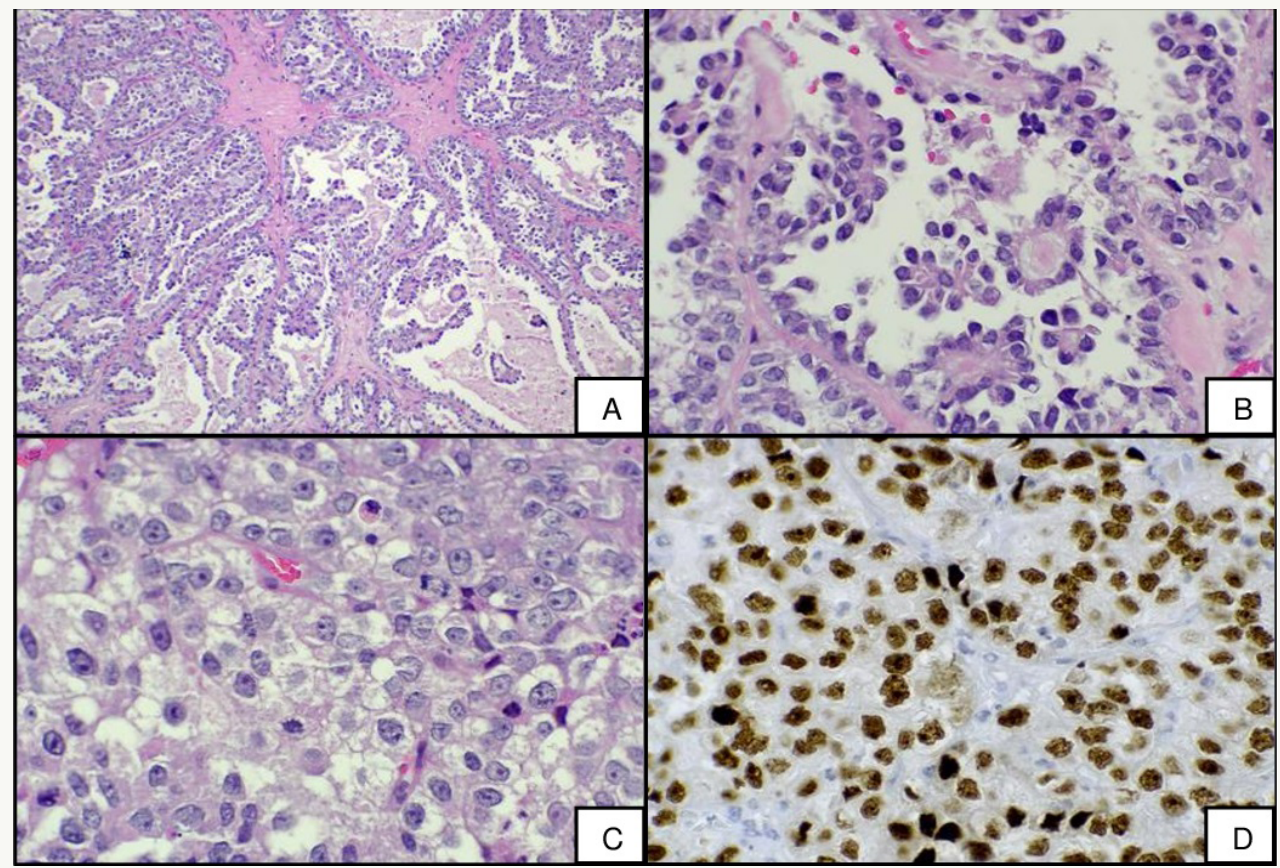

Figure 1. The analysis of the lesion from transurethral resection shows: A. Polymorphic epithelial proliferation with papillary, tubulocystic and solid pattern, the stroma is hyalinized (hematoxylin-eosin stain, 40x); B. Papillary pattern showing hobnail cells and hyalinized stroma (hematoxylin-eosin stain, 400x); C. Solid pattern consisting of atypical epithelial cells with clear cytoplasm and high number of mitotic figures and apoptotic bodies (hematoxylin-eosin stain, 400x); D. PAX-8 immunohistochemistry with diffuse strong nuclear positivity.

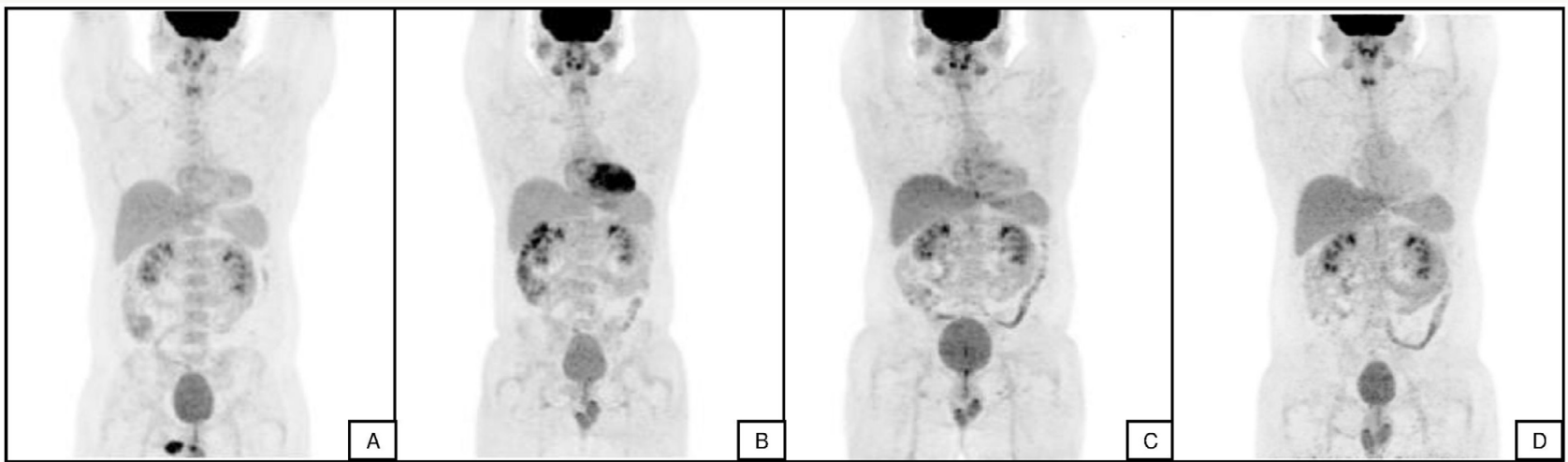

Figure 2. 18F-FDG PET/CT* examination evaluation: A. Baseline 18F-FDG PET/CT (March 15, 2019): abnormal FDG uptake in the membranous urethra (SUV: 11.1) and between the pubis and right ischium (SUV: 15.5); B. 18F-FDG PET/CT after six cycles of chemotherapy (October 22, 2019): complete metabolic response of bone and urethra lesions; C. 18F-FDG PET/CT (February 7, 2020): absence of hypermetabolic lesions suspected of malignancy; D. 18F-FDG PET/CT (June 2, 2020): no evidence of disease, similar to the previous study. *18F-FDG PET/CT = 18Ffluorodeoxyglucose positron emission tomography.

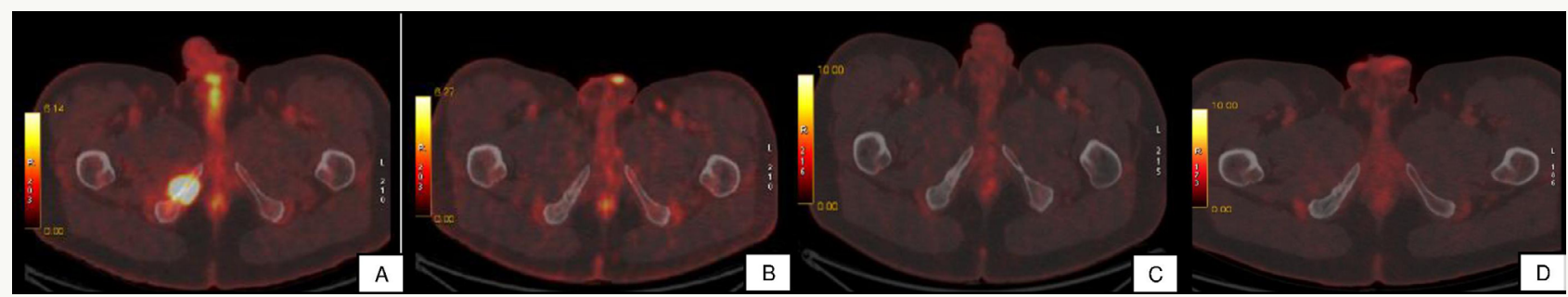

Figure 3. Axial18F-FDG PET/CT* fusion of the pelvis evaluation: A. Baseline 18F-FDG PET/CT (March 15, 2019): hypermetabolic lesion in the urethra and hypermetabolic lytic lesion between the pubis and right ischium; $\mathbf{B}$. 18FFDG PET/CT after six cycles of chemotherapy (October 22, 2019); C. 18F-FDG PET/CT (February 7, 2020) shows absence of hypermetabolic lesions suspected of malignancy; and D. 18F FDG PET/CT ten months after last dose of chemotherapy (June 02, 2020). *18F-FDG PET/CT = 18Ffluorodeoxyglucose positron emission tomography. 
six cycles of systemic chemotherapy, a new ${ }^{18}$ F-FDG PET/CT from 10/22/2019 showed complete metabolic response of bone and urethra lesions (Figures 2B and $3 \mathrm{~B}$ ). A new ${ }^{18} \mathrm{~F}$-FDG PET/CT was performed in 02/07/2020 and showed absence of hypermetabolic lesions suspected of malignancy (Figures 2C and 3C) and at the moment, after ten months of the last chemotherapy, a ${ }^{18}$ F-FDG PET/CT from 06/02/2020 remains with no evidence of disease, similar to the previous study (Figures 2D and 3D). So far, the patient is asymptomatic and without radiological evidence of disease.

\section{DISCUSSION}

Primary urethral cancer is uncommon, being the incidence three times higher in males. Typically the urothelial carcinoma is the most common histological type, followed by squamous cell carcinoma and adenocarcinoma., ${ }^{4,5}$ The CCAU is even more rare and, in contrast to other histological types, the most common clinical presentation is in the female genitourinary tract, often associated with the development of urethral diverticulum. ${ }^{1}$ Several hypotheses about the origin of the CCAU have already been raised: mullerian origin, glandular differentiation of the urothelium, and clonal evolution of nephrogenic metaplasia are the most considered, but this origin remains uncertain. . $^{3,6}$

The pathological characteristics of the CCAU may be tubulocystic, papillary or diffuse pattern, with polygonal cells with large or clear eosinophilic cytoplasm and hobnail cells., ,, 8 In IHC, the CCAU may exhibit positivity for PAX-2, PAX-8, CK-7, p16, p53, CA-125, CAM.2, and AE1/AE3, ${ }^{1}$ in our case, PAX-8 and CA-125 were positive.

Most described clinical manifestations of this malignant neoplasia include hematuria, obstructive symptoms, urinary retention, and recurrent urinary tract infections. ${ }^{9,10}$ However, in two clinical cases reports the clinical presentation was periurethral abscess and fistula, ${ }^{11}$ and chronic symptoms related to urethral trauma from a vehicle accident. ${ }^{9}$ In the case described above, the patient remained oligosymptomatic until diagnosis and subsequent surgery.

The surgical resection of the primary tumor is defined as the most appropriate treatment option and has been adopted in most cases of localized disease. Despite this, considering the rarity of disease, there is no standard recommendation about the extension of the surgery. There is data suggesting that the partial penectomy could be a reasonable treatment approach for a primary localized urethral cancer as well as the urethrectomy with or without cystoprostatectomy for locally advanced disease. ${ }^{10}$ Regarding the treatment with radiation therapy, its applicability and benefit are uncertain. Thus, there are only some clinical cases reports of patients who were treated with radiation therapy for localized disease. $^{2}$
In previous clinical case reports, the time from the primary tumor treatment and the disease recurrence ranged from 5 to 20 months with the most frequent sites of metastasis being lymph nodes, bones, and lungs. ${ }^{6}$ In this case report, the time for recurrence was 30 months with bone and urethra being the site of disease recurrence. Regarding the systemic therapy, platinum-based chemotherapy is the most commonly used for primary urethral cancer with uncertain response rate and no data of survival benefit. ${ }^{10}$ In this context, one case report described absence of response rate with MVEC (mitoxantrone, vinblastine, epirubicin, and cisplatin) after relapse and the patient died 10 months after surgery. ${ }^{13}$ On the other hand, another case report of a patient with metastatic disease at diagnosis demonstrated a disease stability and clinical benefit with cisplatin plus gemcitabine after 6 cycles, but radiological exams showed disease progression three months later. This patient was treated again with cisplatin and gemcitabine, followed by gemcitabine alone and after new disease progression he received nabpaclitaxel, with 29 months of overall survival. ${ }^{6}$

Therefore, this report describes a male patient with primary clear cell adenocarcinoma of the urethra with the longest disease-free survival after surgery reported so far and the first clinical case with complete radiological response after platinumbased chemotherapy.

\section{CONCLUSION}

Male urethral clear cell adenocarcinoma is a rare neoplasia, with only 10 clinical cases described in the medical literature. This tumor has an aggressive behavior, even in the localized disease scenario, and consequently a poor 5-year survival. Due to its rarity, data about the best approach to the disease are scarce and divergent. Surgery is the most appropriate treatment for localized disease and platinum-based chemotherapy seems to be a good option for systemic treatment, but optimal treatment is not yet wellestablished and further data and studies are needed.

\section{ACKNOWLEDGEMENTS}

We thank Dr. Aderivaldo Cabral Dias Filho for explaining the surgical procedure performed, Dr. Luciano M. do Prado Jr. and Dr. Marcus E. A. Segura for making the images available.

\section{ETHICAL CONSIDERATIONS}

This case report received approval from the institution's research ethics committee, and has been approved under the registration number 3.846.377 and CAAE 28202020.4.0000.5650 in the Plataforma Brasil.

\section{CONFLICT OF INTEREST STATEMENT}

The authors declare that the research was conducted in the absence of any commercial or financial relationships that could be construed as a potential conflict of interest. 


\section{REFERENCES}

1. Venyo AKG. Clear cell adenocarcinoma of the urethra: review of the literature. IntJSurg Oncol.2015;2015:79235.

2. CantrellBB, Leifer G, DeklerkDP, EgglestonJC. Papillary adenocarcinoma of the prostatic urethra with clearcell appearance. Cancer. 1981 Dec;48(12):2661-7.

3. Sun $\mathrm{K}$, Huan Y, Unger PD. Clear cell adenocarcinoma of urinary bladder and urethra: another urinary tract lesion immunoreactive for P504S. Arch Pathol Lab Med. 2008 Sep;132(9):1417-22.

4. Visser O, Adolfsson J, Rossi S, Verne J, Gatta G, Maffezzini $M$, et al. Incidence and survival of rare urogenital cancers in Europe. EurJ Cancer. 2012 Mar;48(4):456-64.

5. Swartz MA, Porter MP, Lin DW, Weiss NS. Incidence of primary urethral carcinoma in the United States. Urology. 2006 Dec;68(6):1164-8.

6. Liu SV, Truskinovsky AM, Dudek AZ, Ramanathan RK. Metastatic clear cell adenocarcinoma of the urethra in a male patient: report of a case. Clin Genitourin Cancer. 2012 Mar; 10(1):47-9.

7. Oliva E, Young RH. Clear cell adenocarcinoma of the urethra: a clinicopathologic analysis of 19 cases. Mod Pathol. 1996 May;9(5):513-20.

8. Nakatsuka S, Taguchi I, Nagatomo T, Yamane $M$, Sugio K, Yoshino $R$, et al. A case of clear cell adenocarcinoma arising from the urethral diverticulum: utility of urinary cytology and immunohistochemistry. Cytojournal. 2012;9(1):11.
9. Gandhi J, Khurana A, Tewari A, Mehta A. Clear cell adenocarcinoma of the male urethral tract. Indian J Pathol Microbiol. 2012 Jul;55(2):245-7.

10. Janisch F, Abufaraj M, Fajkovic H, Kimura S, Iwata $T$, Nyirady $P$, et al. Current disease management of primary urethral carcinoma. Eur Urol Focus. 2019 Sep;5(5):722-34.

11. Varachhia SA, Goetz L, Persad R, Naraynsingh V. Clear cell carcinoma of the male urethra presenting as periurethral abscess with fistulae. J Pelvic Med Surg. 2009 Jul/Aug; 15(4):221-3.

12. Lewis S, Pal M, Bakshi G, Ghadi YG, Menon S, Murthy $V$, et al. Case reports High-dose-rate brachytherapy - a novel treatment approach for primary clear cell adenocarcinoma of male urethra. J Contemp Brachytherapy. 2015 Jun;3(3):248-51.

13. Gogus C, Baltaci S, Orhan D, Yaman O. Clear cell adenocarcinoma of the male urethra. Int J Urol. 2003 Jun; 10(6):348-9.

14. Seseke F, Zöller G, Kunze E. Clear cell adenocarcinoma of the male urethra in association with so-called nephrogenic metaplasia. Urol Int. 2001;67(1):104-8.

15. Sugimura R, Kawahara T, Noguchi G, Takamoto D, Izumi K, Miyoshi Y, et al. Clear cell adenocarcinoma of the prostatic urethra: a case report. IJU Case Rep. 2018 Nov;2(1):19-22. 